\title{
Postmortem Blood and Tissue Changes for Estimation of Time of Death
}

\author{
Supriya Das ${ }^{1}$, S.K. Panda ${ }^{1 *}$, A.P. Acharya ${ }^{1}$, U.K. Mishra ${ }^{2}$, A.K. Kundu ${ }^{3}$, \\ B.N. Mohanty ${ }^{4}$ and I. Ali ${ }^{1}$
}

${ }^{1}$ Department of Veterinary Pathology, ${ }^{2}$ Department of Veterinary Anatomy, ${ }^{3}$ Department of Veterinary Physiology, ${ }^{4}$ Department of Veterinary Parasitology, College of Veterinary

Science \& Animal Husbandry, Odisha University of Agriculture \& Technology, Bhubaneswar, India

*Corresponding author

\section{A B S T R A C T}

The present work was carried out in Department of Veterinary pathology, College of Veterinary Science and Animal Husbandry, OUAT,

Keywords

$\mathrm{Hb}, \mathrm{TEC}, \mathrm{TLC}$,

Time of death

Article Info

Accepted:

04 August 2019

Available Online:

10 September 2019

Bhubaneswar to study changes of different blood parameters in postmortem blood with respect to time passed since death. Postmortem changes of different body tissues like liver, heart, kidney etc. were also studied. Blood samples collected in EDTA vial were analysed for estimation of $\mathrm{Hb}$, TEC, TLC and $\mathrm{pH}$. Hb in postmortem blood had no correlation with time passed since death. But TEC, TLC and $\mathrm{pH}$ were strongly correlated with time passed since death. As time since death increased TLC as well as TEC decreased but $\mathrm{pH}$ of post-mortem blood increased. There were also some remarkable tissue changes occur in postmortem samples as time passed since death increased. These changes can help in rough approximation of time of death estimation.

\section{Introduction}

After death, a sequence of changes i.e. a series of chemical as well as physical reactions naturally occur in the dead body. These changes are called as the postmortem changes. Postmortem interval (PMI) or time of death is the time that has elapsed since the animal has died. Post mortem interval estimation is very important in human as well as in animal forensic death investigations (Brooks, 2016). Despite of various research on this aspect, accuracy in estimation of time of death cannot be significantly improved and there is not a 
single reliable method for estimating time of death accurately till now. As evaluation of accurate time of death is a very difficult task because it is influenced by a lot of environmental factors so we cannot use a single method for it. As very limited research has been done in these aspects especially in veterinary field till now, more studies are needed in this area. After death there are many changes occur in body. So there must be changes in different body tissue as well as in blood with increase in time passed since death. If these changes can be correlated with time since death it may help in rough approximation of time of death. The blood sample collected in EDTA vial were analysed for estimation of Haemoglobin, TEC, TLC and EDTA. Total number of RBC and WBC strongly correlated with time passed since death though they are inversely correlated. Total number of Platelet strongly correlated with time passed since death (Kundu SD, 2017). Again degeneration and autolysis of different body tissues also occur progressively after death. These progressive changes may be correlated with time passed since death and it can be act as a parameter for estimation of time of death along with other parameters. Hence in the present study, attempt was taken to correlate tissue as well as blood changes after death with time passed since death.

\section{Materials and Methods}

\section{Hematological studies}

For haematological study blood samples collected from 12 dead goats of apparently healthy herd immediately after death in accidental cases i.e. $0 \mathrm{hr}$ which was equivalent to antemortem sample followed by series of collection at an interval of 6hrs upto 24hrs after death. Postmortem blood sample were collected by piercing jugular vein, femoral vein, Common Carotid artery and on dissection from chambers of Heart with the help of $5 \mathrm{ml}$ disposable syringe. About $5 \mathrm{ml}$ of blood samples were collected and kept into an EDTA vial. To avoid hemolysis, the needle was removed from the syringe before transferring blood to the vial containing the anticoagulant. Additionally, the blood and the anticoagulant were mixed adequately by inverting the vial several times. The blood samples were processed shortly after collection. Then the blood was put for estimation of hematological parameters.

Blood samples were examined to estimate Haemoglobin, Packed cell volume, TLC (Total Leukocyte Count), TEC (Total Erythrocyte Count), DLC (Differential Leukocyte count). $\mathrm{pH}$ of blood samples also estimated by $\mathrm{Ph}$ meter immediately after collection. Estimation of $\mathrm{Hb}(\mathrm{gm} / \mathrm{dl})$, TLC $\left(10^{3} / \mu \mathrm{L}\right)$, TEC $\left(10^{6} / \mu \mathrm{L}\right.$, DLC $(\%)$ were done as per the methods suggested by Coles (1986).

\section{Histopathological studies}

The liver, heart and kidney tissues were collected from 20 goats immediately after slaughter in slaughter house at an in interval of 6 hrs upto 24 hrs. Just after slaughter collection of sample was done with sterile BP blade (500 $\mathrm{g}$ of each organ tissue). At that time sampling of each tissue was done for $0 \mathrm{hr}$ sample which was equivalent to antemortem sample and kept in $10 \%$ formalin in tightly capped jars. The liver, heart and kidney samples which were left after $0 \mathrm{hr}$ sampling were kept in sterile beaker separately and remained as such in room temperature. Sampling at $12 \mathrm{hrs}$ and $24 \mathrm{hrs}$ was done in same above discussed process. The representative portions of different organs with or without gross lesions were fixed in $10 \%$ formal saline solution and were processed by routine histological techniques. For that, first the collected tissues were trimmed into 1-2 mm thick sections and kept in $10 \%$ formal saline solution to be fixed 
properly. The fixed tissues were washed overnight washing in running tap water. Then dehydration of samples was done in ascending grades of alcohol i.e., 70\%, $80 \%, 90 \%$, absolute alcohol. After dehydration clearing was done with xylene. Then the tissues were embedded in paraffin maintained at a temperature of 58-60 degree Celsius in an incubator and paraffin tissue blocks were prepared with help of brass moulds. Tissue sections were cut at 4-5 $\mu \mathrm{m}$ thickness with help of microtome and stained by routine Hematoxylin and Eosin method (Anderson and Gordon, 1996). After staining the stained slides were mounted DPX mountant and with cover slip. For histopathological examination the prepared slides were examined under microscope.

\section{Results and Discussion}

\section{Hematological studies}

For haematological study total 60post-mortem blood samples were taken in different time interval after death from 12 postmortem cases. Different haematological parameters like $\mathrm{Hb}$, TEC, TLC, PCV as well as Ph of blood samples were studied. The average value of all haematological parameters at different time interval in post-mortem blood of goat were compared with 0 hour of death which is equivalent to antemortem blood.

The average values of all haematologic parameters at different time interval (after death) are presented in table 1 . The mean $\pm S E$ at different time interval considered as statistically significant with $\mathrm{P} \leq 0.05$.

\section{Haemoglobin}

Haemoglobin $(\mathrm{Hb} \%)$ values in, 6 hours, 12 hours, 18 hours and 24 hours post-mortem were $10.62 \pm 0.37,10.62 \pm 0.37,10.43 \pm 0.37$, $10.23 \pm 0.39$ and $9.96 \pm 0.36$ indicating no much difference of $\mathrm{Hb}$ at different time interval as compared to $\mathrm{Ohr}$ which is equivalent to antemortem blood of death (Table 1, Chart 1).

\section{Total erythrocyte count (TEC)}

TEC $\left(10^{5} \mu l\right)$ values in $0 \mathrm{hrs}, 6 \mathrm{hrs}, 12 \mathrm{hrs}$, $18 \mathrm{hrs} \& 24 \mathrm{hrs}$ of post-mortem were 11.44 $\pm 0.57,11.09 \pm 0.50,8.32 \pm 0.41,5.00 \pm 0.27$ and 2.83 0.25 (Table 1, Chart 2) indicating decrease in TEC with increase in time after death. In this TEC different time interval were compared with Ohour of death which is equivalent to antemortem blood. Here there is no significant difference between 0 hour and 6 hour of post-mortem but there is significant difference after wards i.e. 18 hour $\& 24$ hour.

\section{Total leukocyte count (TLC)}

TLC $\left(10^{4} \mu l\right)$ values in 0 hour, 6 hours, 12 hours, 18 hours, 24 hours post-mortem were $9.64 \pm 0.59,9.44 \pm 0.57,8.6 \pm 0.57,7.02 \pm 0.51$ and $5.17 \pm 0.44$ (Table 1, Chart 3) indicating significant decrease in TEC with increase in time after death $(\mathrm{P} \leq 0.05)$. In this TLC different time interval were compared with 0 hour of death which is equivalent to antemortem blood. Here there is no significant difference between 0 hour 6 hour and 12 hour of post-mortem but there is significant difference afterward i.e. 18 hour $\& 24$ hour.

\section{pH}

$\mathrm{pH}$ values in 0 hrs, $6 \mathrm{hrs}, 12 \mathrm{hrs}, 18 \mathrm{hrs} \& 24$ hrs of post-mortem were $7.42 \pm 0.04,7.27$ $\pm 0.05,6.99 \pm 0.07,6.55 \pm 0.12$ and $6.12 \pm 0.07$ (Table 1, Chart 4) indicating significant decrease in $\mathrm{pH}$ with increase in time (6 hours, 12 hours, 18 hours, 24 hours post-mortem after death) than $0 \mathrm{hr}$ with a significant difference between the groups $(\mathrm{P} \leq 0.05)$. In this $\mathrm{pH}$ different time interval were compared with 0 hour of death which is equivalent to antemortem blood. 
Table.1 Mean \pm SE value of different haematological parameters of post-mortem blood in different time interval $(\mathrm{P} \leq 0.05)$

\begin{tabular}{|l|l|l|l|l|l|}
\hline $\begin{array}{l}\text { Haematological } \\
\text { Parameter }\end{array}$ & 0 hour & 6 hours & 12hours & 18 hours & 24 hours \\
\hline Hb(g/dl) & $10.62 \pm 0.37$ & $10.62 \pm 0.37$ & $10.43 \pm 0.37$ & $10.23 \pm 0.39$ & $9.96 \pm 0.36$ \\
\hline PCV $(\%)$ & $30.50^{\mathrm{a}} \pm 0.95$ & $29.75^{\mathrm{a}} \pm 0.99$ & $26.75^{\mathrm{b}} \pm 1.12$ & $22.50^{\mathrm{c}} \pm 1.17$ & $17.42^{\mathrm{d}} \pm 0.48$ \\
\hline TEC $\left(\mathbf{1 0}^{\mathbf{5}} \boldsymbol{\mu l}\right)$ & $11.44^{\mathrm{a}} \pm 0.57$ & $11.09^{\mathrm{a}} \pm 0.50$ & $8.32^{\mathrm{b}} \pm 0.41$ & $5.00^{\mathrm{c}} \pm 0.27$ & $2.83^{\mathrm{d}} \pm 0.25$ \\
\hline TLC $\left(\left(\mathbf{1 0}^{4} \boldsymbol{\mu l}\right)\right.$ & $9.64^{\mathrm{a}} \pm 0.59$ & $9.44^{\mathrm{a}} \pm 0.57$ & $8.6^{\mathrm{a}} \pm 0.57$ & $7.02^{\mathrm{b}} \pm 0.51$ & $5.17^{\mathrm{b}} \pm 0.44$ \\
\hline Ph & $7.42^{\mathrm{a}} \pm 0.04$ & $7.27^{\mathrm{b}} \pm 0.05$ & $6.99^{\mathrm{c}} \pm 0.07$ & $6.55^{\mathrm{d}} \pm 0.12$ & $6.12^{\mathrm{a}} \pm 0.07$ \\
\hline
\end{tabular}

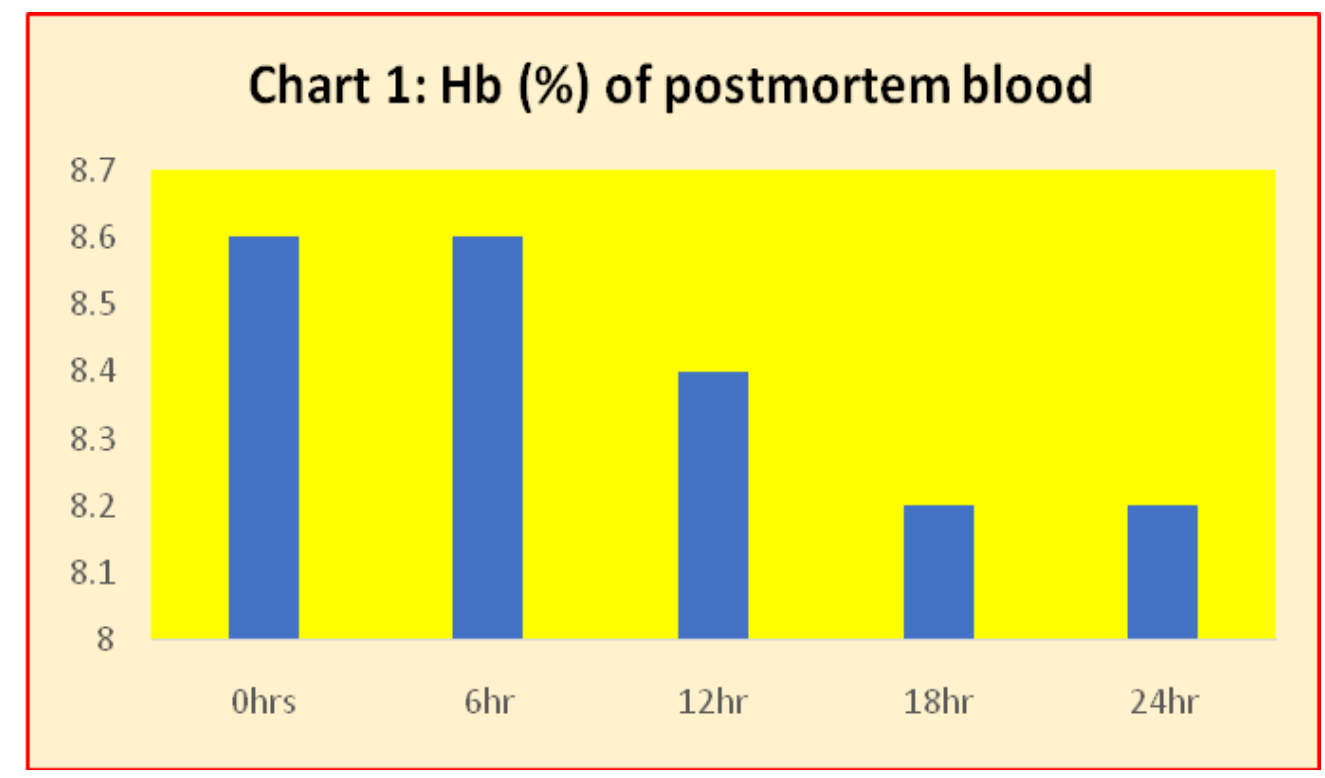

\section{Chart 2: TEC(105 $\mu l)$ of postmortem blood}

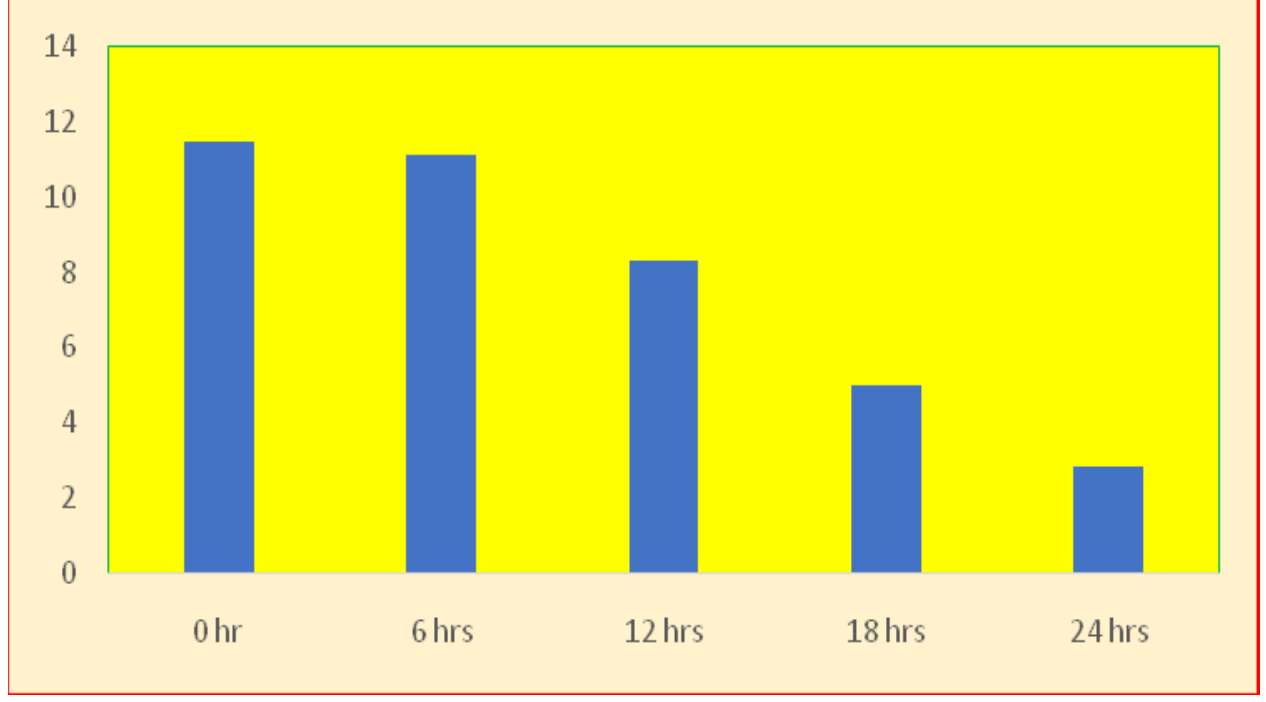


Chart 3: TLC $(104 \mu)$ of postmortem blood of goat

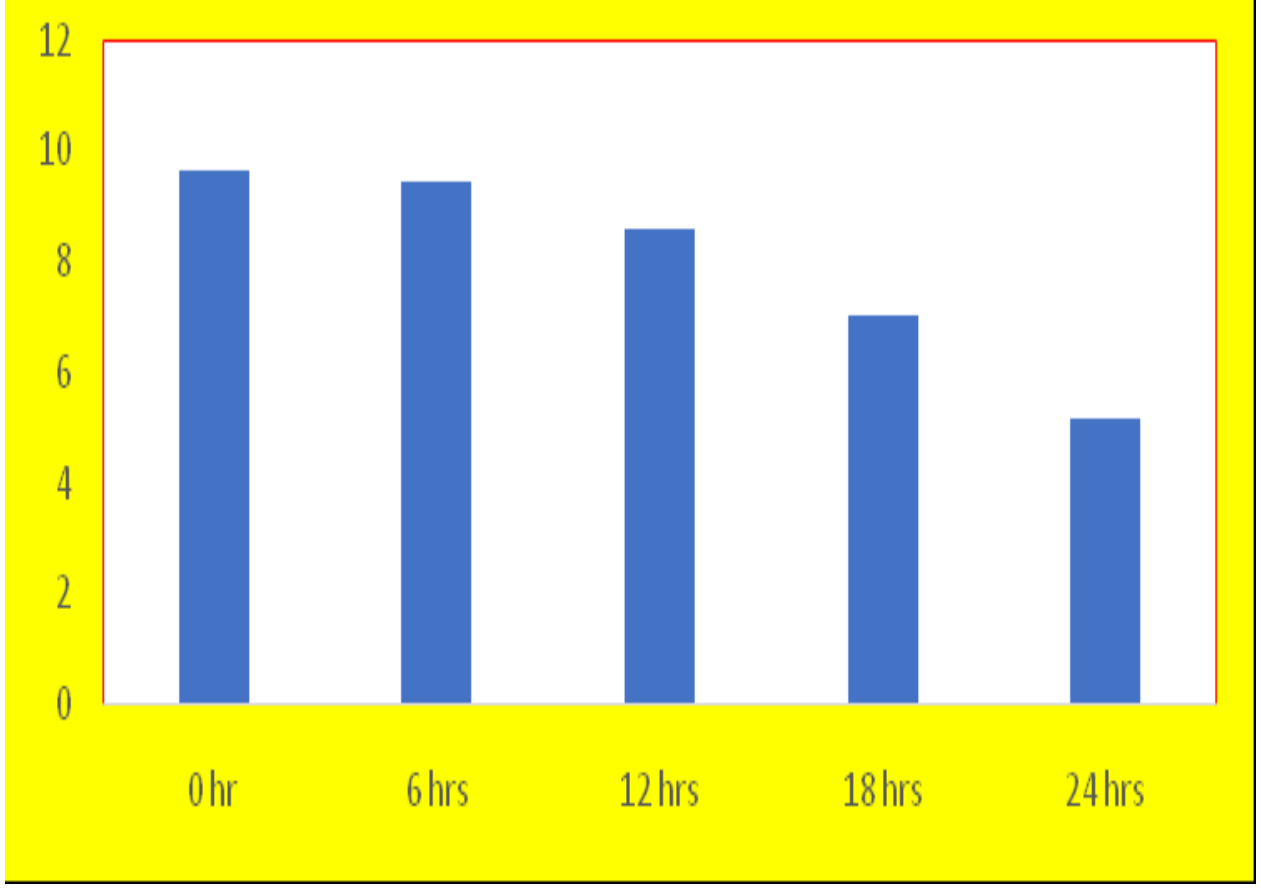

Chart 4: pH of postmortem blood of goat

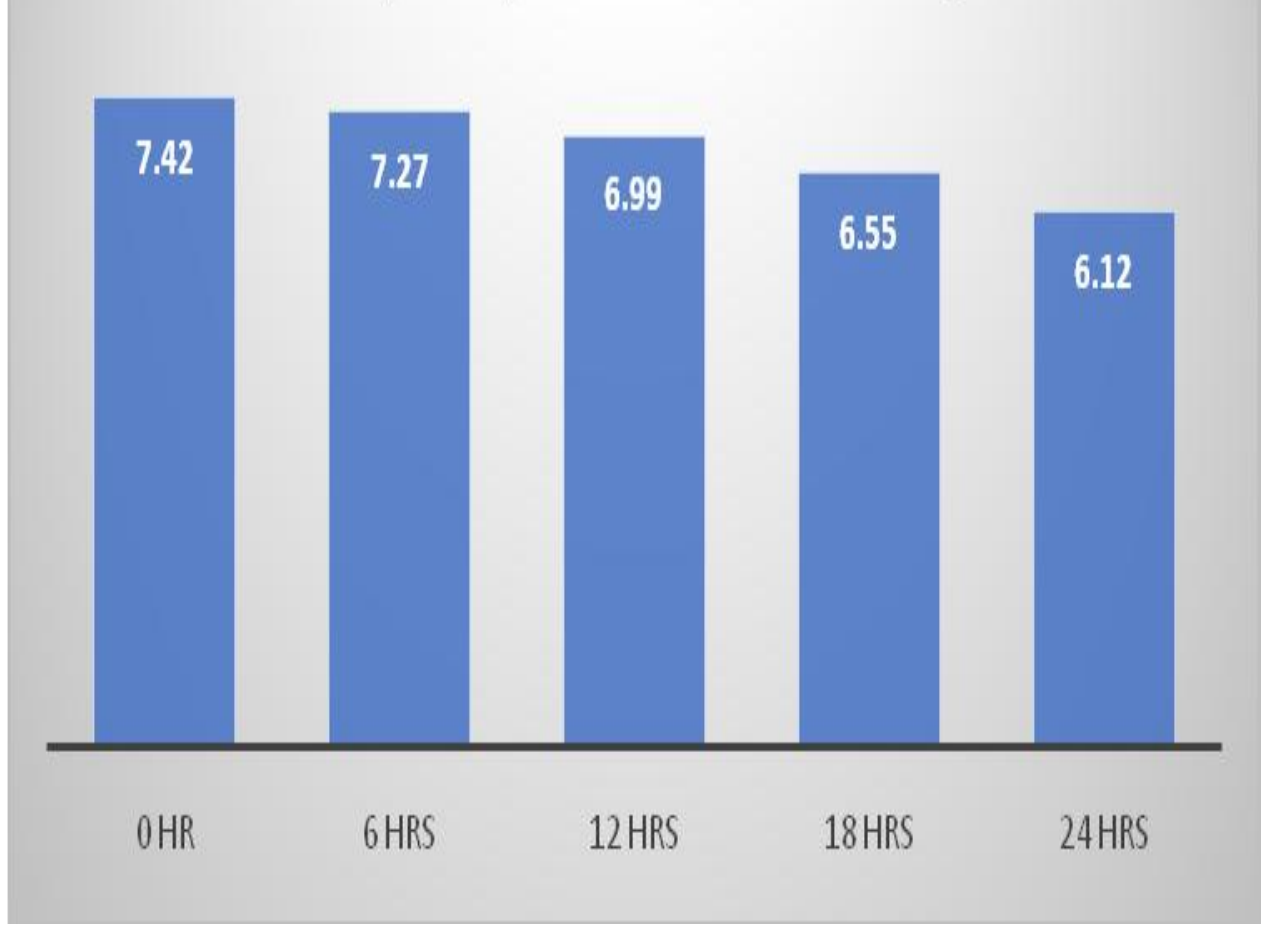




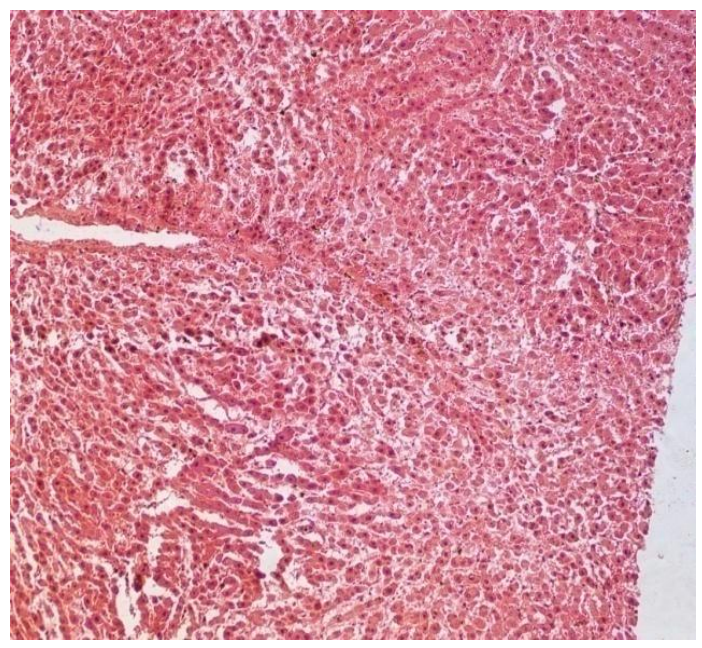

Fig. 1: Photomicrograph of liver showing condensation of nucleus with increase granularity (H \& E × 100)

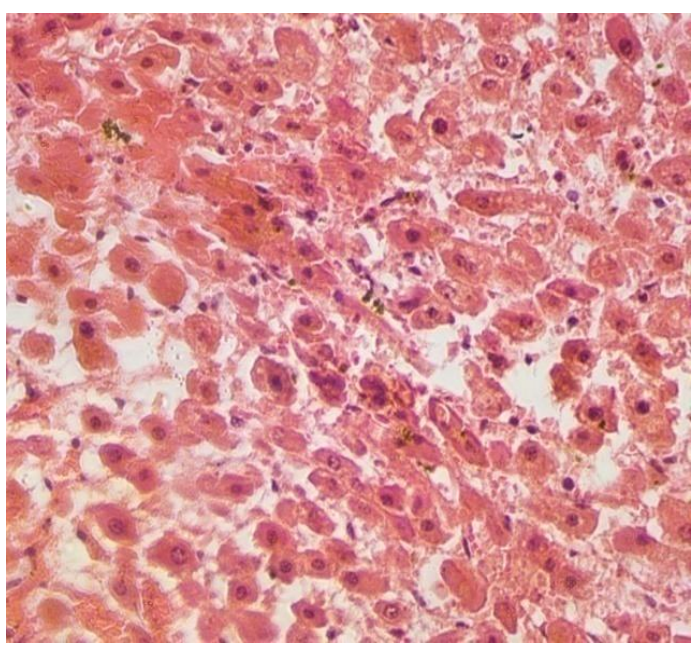

Fig. 2: Photomicrograph of liver showing condensation of nuclei in hepatocytes $(H$

$\& E \times 400)$

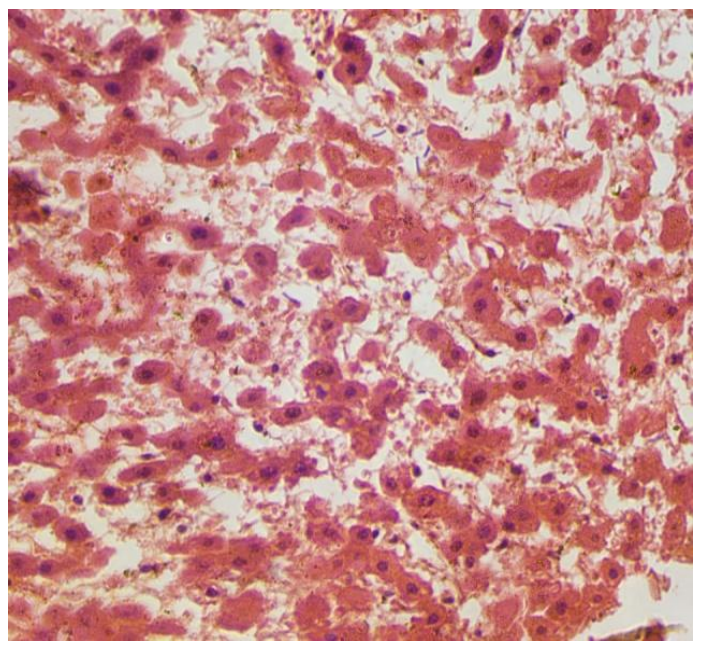

Fig. 3: Photomicrograph of liver showing disintegration of nucleus in some hepatocytes with disruption of chords and increase sinusoidal space ( $H$ \& E $\times 400)$

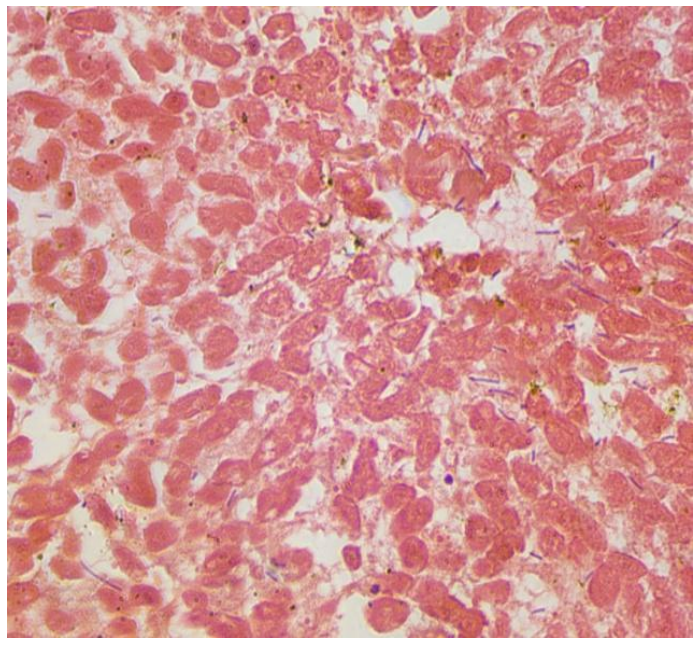

Fig.4: Photomicrograph of liver showing complete disintegration of nucleus with many saprophytes (H \& E × 400) 


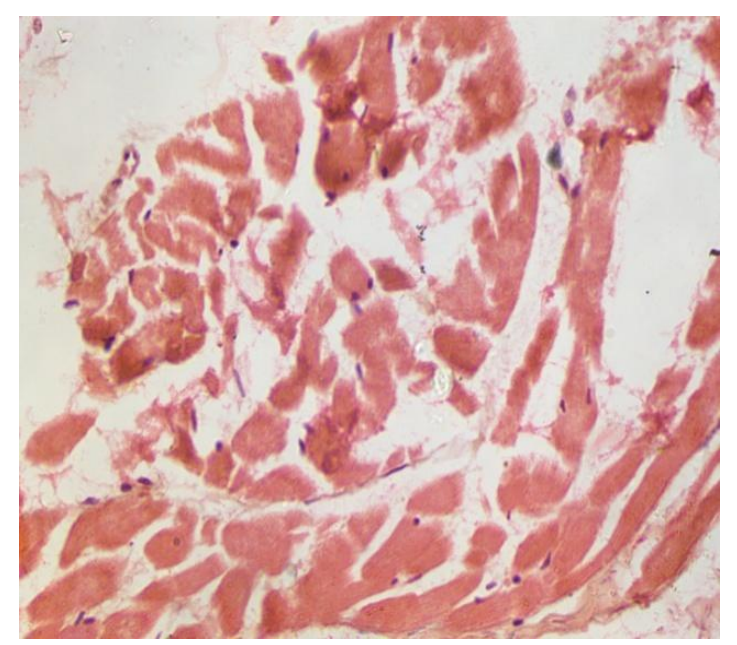

Fig. 5: Photomicrograph of heart showing pyknotic nuclei, loss of granularity of cytoplasm in myofibrils (H \& $E \times 400)$

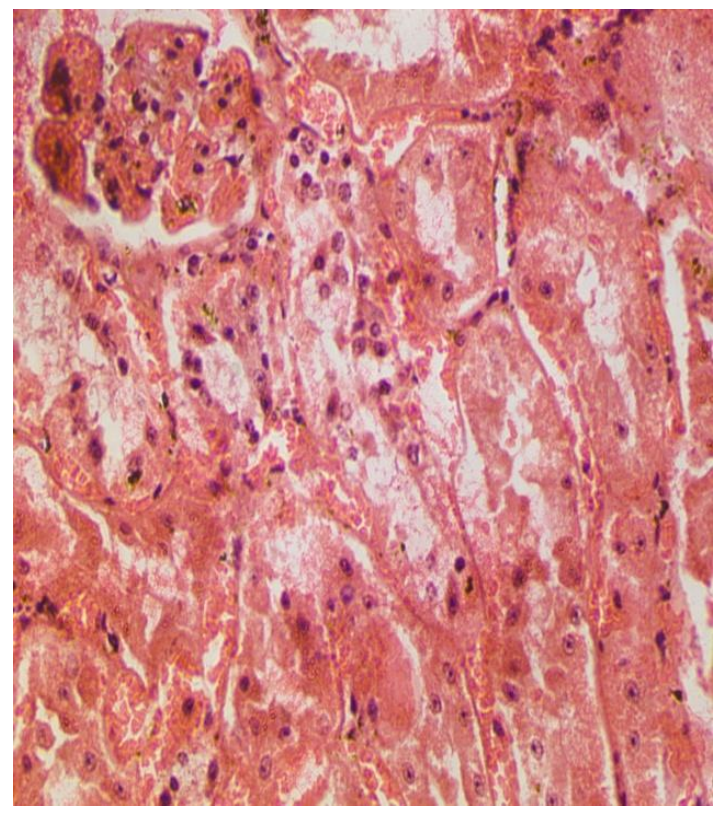

Fig. 7: Photomicrograph of kidney showing cellular swelling with increase granularity of cytoplasm of tubular epithelium and disruption of tubular ebithelium at manv blaces(H \& E ×400)

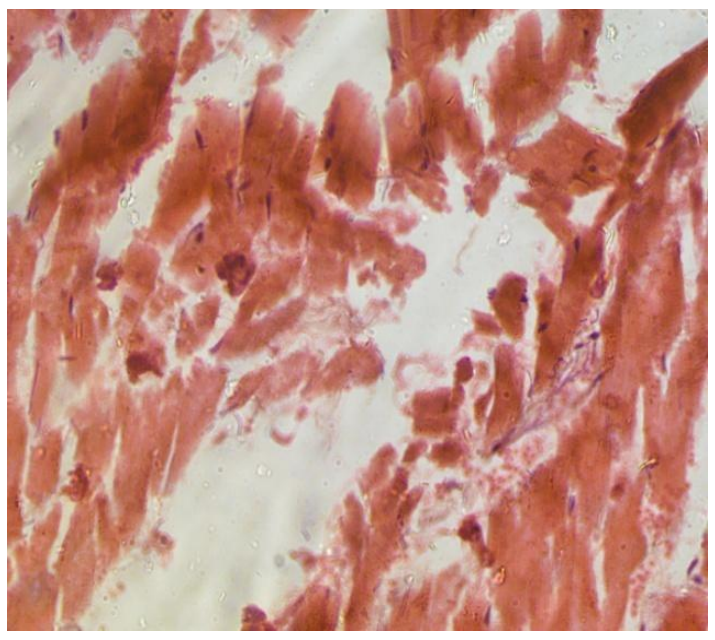

Fig. 6: Photomicrograph of heart showing loss of granularity polarity, detachment of myofibrils and pyknosis, disintegration of nucleus

(H \& E ×400)

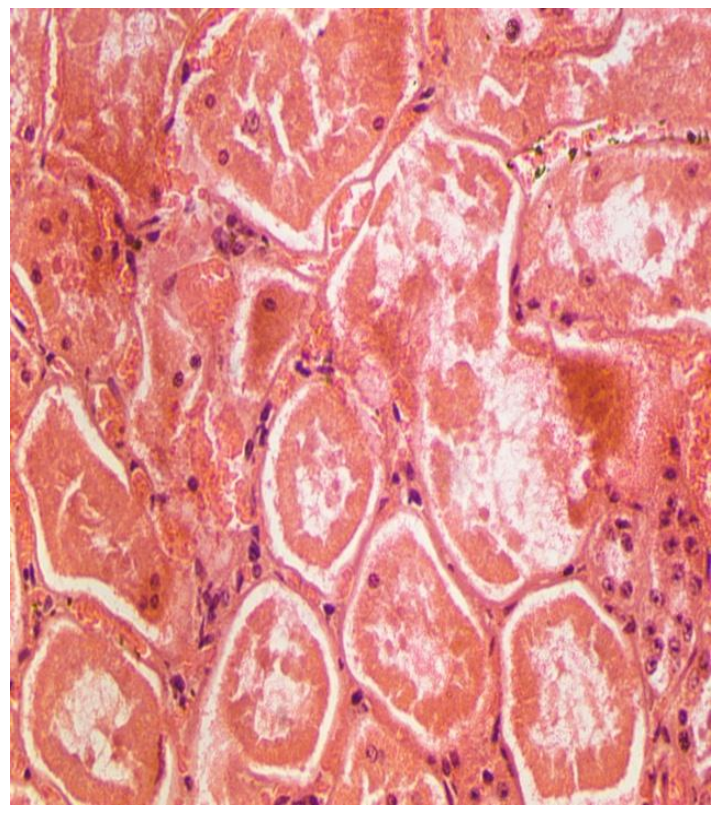

Fig. 8: Photomicrograph of kidney showing disintegration of tubular epithelium( $H \& E \times 400)$ 


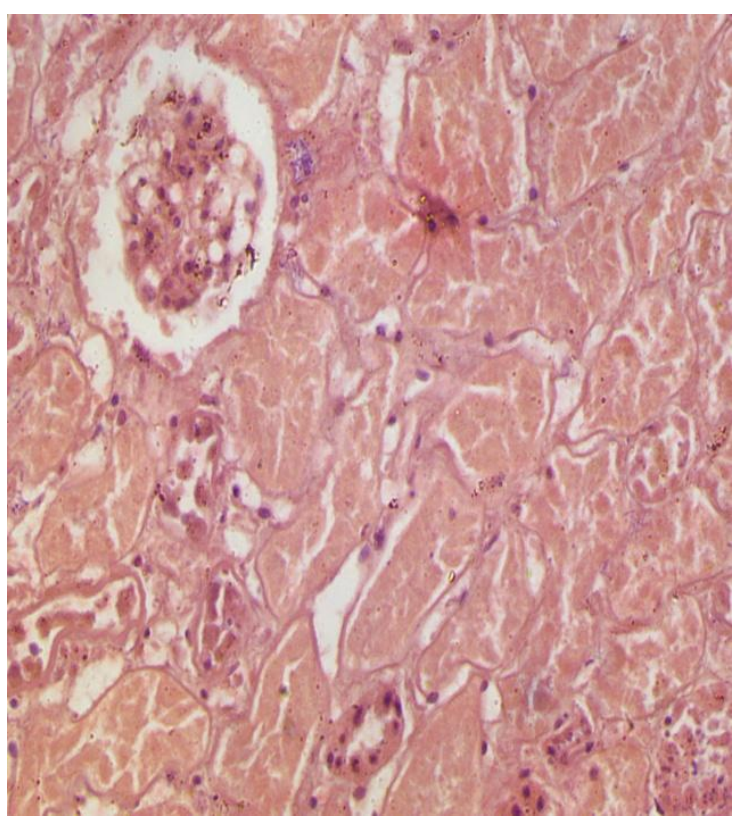

Fig. 26: Photomicrograph of kidney showing disintegration and dissolution of nuclei of some tubular epithelial cells with collapse of glomeruli(H \& E $\times 400$ )

\section{Histopathological studies}

Histopathologically, the liver specimens collected at 12-hours of slaughter showed condensation of nucleus along with increased granularity of cytoplasm in the hepatocytes (Fig. 1 to 2). At 24-hours of slaughter the liver showed disintegration of nucleus in some hepatocytes with disruption of chords and increase sinusoidal space (Fig. 3). In some places there was complete disintegration of nucleus of hepatocytes with many invading saprophytes (Fig. 4). The heart specimens at 12-hours of slaughter showed heart showing pyknotic nuclei, loss of granularity of cytoplasm in myofibrils (Fig. 5). At 24-hours, the heart specimens showed loss of granularity polarity, detachment of myofibrils and pyknosis, disintegration of nucleus (Fig. 6). There was partial liquefaction in
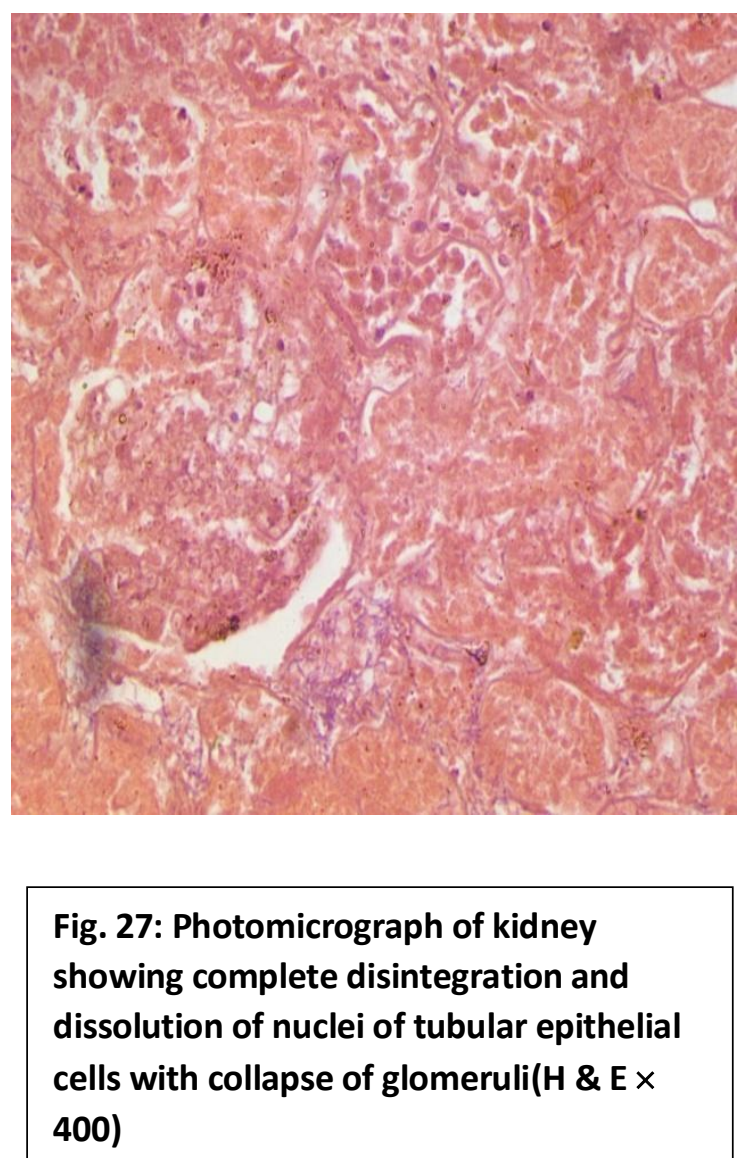

Fig. 27: Photomicrograph of kidney showing complete disintegration and dissolution of nuclei of tubular epithelial cells with collapse of glomeruli(H \& E X 400)

myofibrils at some places. At 12 hours kidney showed, cellular swelling with increase granularity of cytoplasm of tubular epithelium and disruption of tubular epithelium at many places (Fig. 7 to 8). There were swollen glomerulin some places but architecture was maintained. At 24 hours disintegration and dissolution of nuclei of some glomerular epithelial cells with collapse of glomeruli (Fig. 9 to 10). The architecture was disturbed and disruption of epithelium was prominent at some places.

In haematological study total 60 post-mortem blood samples were taken in different time interval after death from 12 postmortem cases. Different haematological parameters like $\mathrm{Hb}, \mathrm{TEC}, \mathrm{TLC}, \mathrm{PCV}$ as well as $\mathrm{pH}$ of blood samples were studied. The average value of all haematological parameters at 
different time interval in post-mortem blood of goat were compared with 0 hour of death which is equivalent to antemortem blood. Haemoglobin $(\mathrm{Hb} \%)$ values in were $10.62 \pm$ $0.37,10.62 \pm 0.37,10.43 \pm 0.37,10.23 \pm 0.39$ and $9.96 \pm 0.36$ at $0 \mathrm{hrs}, 6 \mathrm{hrs}, 12 \mathrm{hrs}, 18 \mathrm{hrs}$ and $24 \mathrm{hrs}$ respectively indicating no much difference of $\mathrm{Hb}$ at different time interval as compared to $\mathrm{Ohr}$ which is equivalent to antemortem blood of death. According to Kundu (2017) the values of Haemoglobin and Haematocrit in post-mortem blood were not correlated with time passed since death. TEC $\left(10^{5} \mu l\right)$ values in 0 hour, 6 hour, 12 hour, 18 hour and 24 hour post-mortem were $11.44 \pm 0.57, \quad 11.09 \pm 0.50, \quad 8.32 \pm 0.41$, $5.00 \pm 0.27$ and $2.83 \pm 0.25$ indicating decrease in TEC with increase in time after death. In this TEC different time interval were compared with 0 hour of death which is equivalent to antemortem blood. Here there is no significant difference between 0 hour and 6 hour of post-mortem but there is significant difference afterwardsi.e18 hour \& 24 hour. $\operatorname{TLC}\left(10^{4} \mu l\right)$ values in 0 hour, 6 hour, 12 hour, 18 hour and 24 hour post-mortem were $9.64 \pm 0.59, \quad 9.44 \pm 0.57, \quad 8.6 \pm 0.57, \quad 7.02 \pm 0.51$ and $5.17 \pm 0.44$ indicating there is significant decrease in TEC with increase in time after death. In this TLC different time interval were compared with 0 hour of death which is equivalent to antemortem blood. Here there is no significant difference between 0 hour 6 hour and 12 hour of post-mortem but there is significant difference afterward i.e. 18 hour \& 24 hour. As with time passed since death there is lysis of RBC as well as WBC occur due to degenerative changes so their total number gradually decreases. Kundu SD (2017) said that hemogram in blood after death act as a tool to estimate Time Passed since Death. She found that total number of RBC and WBC strongly correlated with Time passed since Death, though they are inversely correlated. $\mathrm{pH}$ values were $7.42 \pm 0.04$, $7.27 \pm 0.05, \quad 6.99 \pm 0.07, \quad 6.55 \pm 0.12$ and
$6.12 \pm 0.07$ in 0 hour, 6 hour, 12 hour, 18 hour and 24 hour post-mortem indicating significant decrease in $\mathrm{pH}$ with increase in time upto $24 \mathrm{hrs}$ of post death. The $\mathrm{pH}$ of blood decreases as after death there is anaerobic glycolysis occur so lactic acid releases which decrease the $\mathrm{pH}$ of blood. Due to autolysis of body after death the metabolites and ions such as hydrogen ions, dihydrogen phosphate ions, bicarbonate and carbon dioxide were produced and accumulated in blood with lowering the $\mathrm{Ph}$. In a study Donalson and Lamont (2013) observed the changes in blood Ph upto 96 hrs of post death in blood collected from pig, rat corpses and also in blood from human and rat stored in-vitro. They showed that blood $\mathrm{Ph}$ decreases from 7.4 to 5.1 in the blood collected from corpse and rate and extend of changes varied with different species. The concentration of lactate increased and then remained at an elevated level, so $\mathrm{pH}$ decreases as time passes after death and in human and pig the changes in concentration were different as compared to rat.

Histopathological examination of liver sample collected after $12 \mathrm{hrs}$ of showed that there was increase in granularity of hepatocytes with condensation of nucleus and after $24 \mathrm{hrs}$ it was observed that there was disintegration of nucleus of some hepatocytes with increase in sinusoidal spaces. In a similar histopathological study on goat by Chowdhury et al., (1970) showed that after 6 hrs of post death. There were focal areas of autolysis with increase granularity of hepatocytes then after 12 hrs disintegration and rarefaction of nuclei in hepatocytes started and the hepatocyte cytoplasm became eosinophilic with replacing the basophilic character of liver cells. At 24 hrs nuclear pyknosis begin with merging of cell outline of hepatocytes. They tried to correlate these histopathological changes with time passed since death. According to Kushwaha et al., at 
$30^{\circ} \mathrm{C}$ mild autolytic changes were seen beginning form $24 \mathrm{hrs} \& \mathrm{~b} / \mathrm{w} 36$ - 48, hrs, the changes were moderately advanced, then after $72 \mathrm{hrs}$ there were severe autolytic changes with loss of cellular detail as well as cellular architecture. In case of human beings in a study of post death Yamamoto et al., (1997) found that there were autolytic changes, shrinkage of hepatocytes and disruption of hepatic chords with wavy transformation of hepatocytes. On histopathological examination of heart sample collected after 12 of slaughter showed autolytic changes with pyknotic nucleus and loss of granularity of cytoplasm of myofibrils. After 24 hrs of heart showed loss of granularity polarity, detachment of myofibrils and pyknosis, disintegration of nucleus. There were partial liquefaction of myofibrils in some places. Fakhruddin (2002) observed autolytic changes of heart samples collected at $12 \mathrm{hrs}$ of post death. He also reported that there was pyknotic nucleus with granularity of myofibril cytoplasm with detachment of myofibrils. At 24-hours, advanced autolytic changes with loss of polarity and disintegration nucleus was observed in heart samples. There was also partial liquefactions of myofibrils in some places. At 12 hours kidney showed, cellular swelling with increase granularity of cytoplasm of tubular epithelium and disruption of tubular epithelium at many places. There were swollen glomeruli in some places but architecture was maintained. At 24 hours disintegration and dissolution of nuclei of some glomerular epithelial cells with collapse of glomeruli. The architecture was disturbed and disruption of epithelium was prominent at some places. Tandon (1985) studied the histological changes of kidney tissue after death at $30^{\circ} \mathrm{C}$. According to his study at 12 hrs there was cloudy swelling of PCT (proximal convoluted tubules) and DCT (Distal convoluted tubules). Then at $24 \mathrm{hrs}$ diffuse cloudy swelling of renal tubules, glomeruli and also in blood vessels was observed. At 30 hrs, these changes became more intense and diffuse. Then severe autolysis was observed after $48 \mathrm{hrs}$ of post death. Beyond $72 \mathrm{hrs}$ there was complete liquefaction of kidney with bacterial invasion.

Estimation of time of death is very critical task and not a single method can be used for estimation of time of death. The present study indicates that the correlation of progressive changes in the blood as well as the other tissue after death can act as a parameter in estimation of time since death along with other parameters.

\section{Acknowledgment}

The authors are thankful to the Dean, C. V. Sc \& A.H, OUAT Bhubaneswar for providing necessary facilities for smooth conduction and completion of present research work within stipulated time.

\section{References}

Brooks, J.W. 2016. Postmortem changes in animal carcasses and estimation of the postertem interval, Veterinary Pathology, 58(5): 929-940

Chowdhury, S., Chatterjee, P. C. and Banerjee, P. K. 1970. Histological study of liver tissue with regard to determining time of death. J. Indian Acad, of Forensic Sci., 9(1): 19-23.

Donaldson AE and Lamont IL 2013. Biochemistry Changes That Occur after Death: Potential Markers for Determining Post-Mortem Interval. POLS.

Fakhruddin. 2002. Biochemical Changes in Aqueous And Vitreous Humor, Enzymatic And Histopathological Changes In Liver And Heart In Relation To Time Since Death In Slaughtered Goats (Capra hircus). Ph.D. Thesis, College of Veterinary and Animal 
Science Rajasthan Agricultural University, BIKANER.

Kundu, S.D. 2017. Changes in Haemogram in Subjects after Death As A Tool To Estimate Time Passed Since Death. IOSR Journal of Dental and Medical Sciences (IOSRJDMS), 16(10): 19-27.

Kushwaha, V., Yadav, M., Srivastava, A. K and Agarwal, A.Time since death from degenerative changes in the Kidney. $J$ Indian Acad Forensic Med, 32(1): 3741.

Kushwaha, V., Yadav, M., Srivastava, A.K. and Agarwal, A. Time passed since death from degenerative changes in liver. J Indian Acad Forensic Med, 31(4): 320-325.

Mello de Oliveira, J. A and Santos-Martin, C. C. 1995. Enzyme histochemistry of the liver in autopsy material at different post-mortem times. Med. Sci. Law., 35 (3): 201-206.

Mukherjee, J. B. 1975. Estimation of time since death. Review of the methods adopted upto date. J. Ind. Acad. Forensic Sci., 14(2): 28-45.

Nemilow, A.W. 1928. Time of death from tissue changes. Med. Welt., 2: 1337 (Cited by Chowdhury et al., 1970).

Tandon, R. 1985. Time and Temperature controlled histopathological changes in tissue \& organs of Rabbit. International Journal of Forensic Science; 20-25.

Yamamoto, K., Yamamoto, Y., Matsumoto, H., Hayase, T., Ojima, K., Matsubayashi, K., Abiru, H. and Kazuko, K.1997. Unusual post-mortem autolytic change in the liver: wavy transformation of hepatocytes. Medical Science Law, 37(3): 256-9.

\section{How to cite this article:}

Supriya Das, S.K. Panda, A.P. Acharya, U.K. Mishra, A.K. Kundu, B.N. Mohanty and Ali, I. 2019. Postmortem Blood and Tissue Changes for Estimation of Time of Death. Int.J.Curr.Microbiol.App.Sci. 8(09): 43-53. doi: https://doi.org/10.20546/ijcmas.2019.809.007 